SEXUAL ASSAULT

\title{
Risk of undiagnosed infection in men attending a sexual assault referral centre
}

\author{
I Reeves, R Jawad, J Welch
}

Sex Transm Infect 2004;80:524-525. doi: 10.1136/sti.2004.010850

Objectives: To investigate men undergoing forensic examination at the Haven, a specialist centre for the management of sexual assault in south London.

Methods: Forensic notes of 92 men attending the Haven from May 2000 to August 2003 were identified and a detailed review performed.

Results: Males ranged in age from 12 to 51 years, with $83 \%$ within the range $12-35$ years. $78 \%$ were white. Of those who were sexually active ( $n=82$ ) $30 \%$ were heterosexual, $34 \%$ were homosexual, and the remainder provided no information regarding sexual orientation. Most clients were referred by the police $(n=79)$ and attended within 3 days of the alleged assault $(n=73)$. Many of the victims had increased vulnerability to assault-for example, through alcohol or drug consumption or mental health difficulties. One assailant was reported in 61 cases but two or more assailants in 26. Women were reported as assailants in four cases. The sexual assault was frequently accompanied by other physical assault $(n=45)$. Use/threat of a weapon was reported in 18 cases. Rape or attempted rape was reported in 59 cases and was the most common assault. Non-genital injuries were documented in 37 men (40\%). Anal injuries were seen in 31 (34\%). The non-attendance rate at follow up was $41 \%$. Post-exposure prophylaxis (PEP) against HIV was commenced in 31 men (34\%). 23 of the 54 men (43\%) reporting rape and 14 of the $31(45 \%)$ with anal injuries initiated PEP.

Conclusions: The number of men presenting after sexual assault is likely to increase but despite significant risk many do not engage with medical care. This carries an unknown risk of HIV and other STI transmission.

$\mathrm{S}$ exual assault is a widely under-reported and poorly recognised crime. Male rape did not exist as an offence until the legal definition was changed in November 1994. Reported male rape has increased from 150 cases in 1995 to 852 in 2002-3 with 4096 recorded incidents of indecent assault of males in 2002-3. ${ }^{1}$ The Home Office concedes that these trends are "unlikely to reflect the real experiences of such crimes." Although the true prevalence of sexual assault of men in the wider community is not known, one study in a general practice sample reported a $5 \%$ lifetime prevalence with $3 \%$ in adulthood. ${ }^{2}$ The Haven is a sexual assault referral centre (SARC) based within the sexual health directorate of a south London teaching hospital, providing forensic and medical services to victims of sexual assault. The aim of this study was to describe male clients attending the Haven for forensic examination and to investigate their subsequent medical follow up, as this patient population is poorly represented in the medical literature. Forensic examination occurs within 7 days of the assault in order to collect DNA evidence and to document injuries accurately. Clients may be referred by the police or by other medical services; they may also self refer.

\section{METHODS}

The forensic notes of male clients aged 12 years or more attending the Haven from May 2000 to August 2003 were reviewed, focusing on their demographic characteristics, alleged assault, examination findings, and further management-data are missing where clients were unable to give this information. Where possible, comparisons have been made with unpublished data for women clients, using $\chi^{2}$ as a test of significance.

\section{RESULTS}

\section{Clients}

Between May 2000 and August 2003, 122 males were seen ( $6 \%$ of total) and 92 attended for forensic examination. They ranged in age from 12 to 51 years, though $83 \%$ were within the range $12-35$ years. By comparison, $82 \%$ of females at the Haven are within this age range (NS), but men were significantly more likely to be white $(78 \%$ v $58 \%$, $\mathrm{p}<0.001)$. Police referrals accounted for $86 \%$ of clients. Of those that were sexually active $(n=82) 30 \%$ were heterosexual, 34\% were homosexual, and the remainder had no information regarding sexual orientation. Many of the victims had increased vulnerability to assault (table 1).

\section{Assailants}

Most clients alleged being assaulted by one person $(n=61$, $66 \%)$, although a large minority $(n=26,28 \%)$ reported more than one assailant. Female assailants were recorded in four cases, usually as part of a group. In one case two women acted alone in assaulting a learning disabled man.

Most men reported being assaulted by someone they had never met $(\mathrm{n}=29,32 \%)$ or had met only briefly $(\mathrm{n}=22$, $24 \%)$, although many reported that their assailant was well known to them $(n=39,43 \%)$. Women at the Haven were equally likely to report stranger rape $(52 \%$, NS). The majority of assaults perpetrated by complete strangers occurred in public $(69 \%)$ while those by acquaintances were more often in either the client's or assailant's home (67\%).

\section{Assault}

Forty five of the men alleged physical as well as sexual assault with a further two cases in which this was threatened. Eighteen men reported weapon use. Types of assault are shown in table 2 . The most common reported assault was non-consensual receptive anal intercourse (that is, rape). Condom use was reported in only two cases. Ten men who alleged this type of assault reported that the assailant ejaculated inside them. Abbreviations: NGI, non-genital injury; PEP, post-exposure
prophylaxis; SARC, sexual assault referral centre 


\begin{tabular}{|ll|}
\hline Table 1 Client vulnerability & \\
\hline Vulnerability & $\begin{array}{l}\text { Number of } \\
\text { clients }\end{array}$ \\
\hline Alcohol only & 31 \\
Alcohol + other drug use & 9 \\
Other drug use only & 4 \\
Learning disability (LD)/mental health & 7 \\
problems (MHP) only & 5 \\
LD/MHP + alcohol & 5 \\
LD/MHP + other drug use & 9 \\
LD/MHP + alcohol + other drugs & 70 \\
Total & \\
\hline
\end{tabular}

\section{Forensic examination}

Most clients $(\mathrm{n}=73,79 \%)$ were examined within 72 hours of the assault. After initial discussion, six clients declined examination. Thirty two clients had no evidence of injury. Non-genital injury (NGI) was found in 37 cases (40\%). Anal injuries were found in 31 cases $(34 \%)$. Proctoscopy was done in 66 cases and revealed abnormal findings in six clients. Of those men reporting rape, 21 had anal injuries (39\%). Anal injuries were found in a further 10 males who were unsure or unable to give a history of the assault. There were no genital injuries.

\section{Medical management and follow up}

Twenty one of the 92 clients attended follow up at the Haven; 15 clients were referred or chose to attend other services; 2 clients returned to prison. Thus, $41 \%$ did not attend follow up. Seventeen clients commenced hepatitis B vaccination although only two completed the course ( 13 did not attend). HIV post-exposure prophylaxis (PEP) was initiated in 31 cases (34\%). Three clients completed 4 weeks of PEP and one further client did so with brief interruptions in therapy. Twenty one clients did not complete PEP because they did not attend follow up. The remaining six chose to attend other centres. Of the 31 clients with anal injury 14 started PEP $(45 \%)$, as did $23(43 \%)$ of the 54 clients who alleged rape. The 31 clients who reported this type of assault but did not take PEP included four cases of group rape.

Low rates of STIs were demonstrated: two men had perianal warts and one was diagnosed with chlamydia.

\section{DISCUSSION}

The above represents the experience of a London based SARC in dealing with male clients. This sample is likely to be biased in that the majority were police referrals and so stranger rape may be over-represented. The age range was similar to that of female clients but ethnic origin differed. Although data were missing in 33\% it appears that both heterosexual and homo/ bisexual men are at risk. Other authors have reported high levels of non-consensual sex in the latter group. ${ }^{3-5}$ The findings of rape as the most commonly reported sexual assault and the majority reporting a single male assailant are consistent with other larger case series. ${ }^{67}$ Violence has a role with just under half having evidence of non-genital injuries. This may be equally as common in female victims. ${ }^{7}$ Over half the men reporting rape had no anal injuries. This is not inconsistent with assault and indeed genital injuries are frequently absent in female victims. ${ }^{8-10}$ Anal rape in female victims increases the likelihood of finding injuries, ${ }^{10}$ but injury rates are difficult to interpret because of nonstandardised definitions.

Male rape may carry a particularly high risk of HIV transmission. ${ }^{11}$ Although a third of male clients initiated PEP, less than half of those reporting rape or with anal injuries did so and very few completed the course. These rates of uptake

\begin{tabular}{ll} 
Table 2 & Non-consensual activity \\
\hline Non-consensual activity & $\begin{array}{l}\text { Number of } \\
\text { client reports }\end{array}$ \\
\hline Anal & \\
Receptive penile penetration: & 54 \\
$\quad$ Achieved & 5 \\
Attempted & 11 \\
Digital penetration & 2 \\
Foreign body insertion & 27 \\
Oral & 14 \\
$\quad$ Receptive oral intercourse & \\
Insertive oral intercourse & \\
\hline
\end{tabular}

and completion are similar to a study primarily investigating use of PEP after sexual assault in women. ${ }^{12}$ (However, female clients at the Haven have a $41 \%$ PEP completion rate.) The low attendance for follow up raises the risk of missed diagnosis of frequently asymptomatic infections such as rectal gonorrhoea as well as HIV.

The number of male victims of sexual assault presenting to medical services is likely to increase. The current expansion in the provision of services for victims of sexual assault in London may also affect the numbers of men seen. Despite comprehensive services the experience at this centre is that men frequently do not engage with the provision of care after the assault, perhaps because of stigma and psychological difficulties. There is a need for more research into men's perceptions of their risks of assault and sexually transmitted infections as well as their preferences in terms of service provision.

\section{Authors' affiliations \\ I Reeves, R Jawad, J Welch, The Caldecot Centre, 15-22 Caldecot Road, King's College Hospital, Denmark Hill, London SE5 9RS, UK}

Correspondence to: I Reeves, The Caldecot Centre, 15-22 Caldecot Road, King's College Hospital, Denmark Hill, London SE5 9RS, UK; iain.reeves@kingsch.nhs.uk

Accepted for publication 18 August 2004

\section{REFERENCES}

1 Home Office. The British crime survey. London: Home Office publications, 2003.

2 Coxell A, King M, Mezey G, et al. Lifetime prevalence, characteristics and associated problems of non-consensual sex in men: cross-sectional survey $B M J$ 1998;318:846-50.

3 Coxell AW, King MB, Mezey GC, et al. Sexual molestation of men: interviews with 243 men attending a genitourinary medicine service Int J STD AIDS 2000; 11:574-8.

4 Ratner PA, Johnson JL, Shoveller JA, et al. Non-consensual sex experienced by men who have sex with men: prevalence and association with mental health Patient Education and Counselling 2003;49:67-74.

5 Hickson FCI, Davies PM, Hunt AJ, et al. Gay men as victims of non-consensual sex. Arch Sex Behav 1994;23:281-94.

6 Lipscomb GH, Muram D, Speck PM, et al. Male victims of sexual assault. JAMA 1992;267:3064-6.

7 White C. Male rape: emerging trends in manchester. Oral presentation-Sex and abuse: men and rape. London: Royal Society of Medicine, 2003.

8 Biggs M, Stermac LE, Divinsky M. Genital injuries following sexual assault of women with and without sexual intercourse experience. CMAJ 1998; 159:33-7.

9 McGregor MJ, Le G, Marion SA, et al. Examination for sexual assault: Is the documentation of physical injury associated with the laying of charges? A retrospective cohort study. CMAJ 1999;160:1565-9.

10 Sachs CJ, Chu LD. Predictors of genitorectal injury in female victims of suspected sexual assault. Acad Emerg Med 2002;9:146-51.

11 Mastro TD, de Vincenzi I. Probabilities of HIV transmission. AIDS 1996;10(suppl A):S75-S82.

12 Wiebe ER, Comay SE, McGregor, et al. Offering HIV prophylaxis to people who have been sexually assaulted: 16 months' experience in a sexual assault service. CMAJ 2000;162:641-5. 